\title{
Understanding "expert" scientists: Implications for management and organization research
}

\author{
Viktor Dörfler \\ Colin Eden \\ University of Strathclyde, UK
}

\begin{abstract}
This article contributes to the debate about rigor and relevance in management and organization research. The contribution derives from an empirical inquiry into the view of the research process of acknowledged experts in scientific research: Nobel Laureates. The research was conducted through loosely structured indepth interviews with, and background information about, 19 of these expert researchers. The analysis of the interviews suggests emergent themes of the process of successful research that are likely to be relevant to the conduct of management and organization research. We focus on three themes from our interviews: the role of the "big leap" and its relationship to intuition; the significance of seeing both the "big picture" and the detail; and the ways of building and developing successful research teams. We set out our findings from the interviews in the context of the literature from history and philosophy of science and examine the implications for management and organization research.
\end{abstract}

\section{Keywords}

Expert scientists, intuition, master-apprentice relationship, research design, research teams

The starting point of this article was an empirical study, in which we interviewed 19 top scientists, including 17 Nobel Prize winners. In these interviews, we have observed patterns of what these excellent researchers see as characteristics of successful research in their respective fields. Based on this empirical study, we started speculating about what management and organization research (MOR) may learn from consideration of the expressed views and beliefs of some of the top scientists in the world. We do not argue for absolute transferability or unconditional acceptance; we seek to initiate a constructive discussion among management and organization scholars interested in improving MOR.

Over the past two decades, there has been a debate in management journals about the extent to which management research meets the requirements of good science (e.g. Corley and Gioia, 2011; Kilduff, 2006; Pettigrew, 1990; Suddaby, 2014; van de Ven and Johnson, 2006; Weick, 
1995b; Whetten, 1989). Some have argued that rigor involves attending to the tenets of the natural sciences, and others have argued that the field is inadvertently becoming "scientistic" (von Hayek, 1942, 1943, 1944) - in the sense of it missing the best aspects of discovery in the social world of management and organizations. The research reported in this article sought to find out what top scientists believed was important for their own success in research. Our aim was to explore whether their views might have anything of interest to tell us about the ways in which we might conduct research in management and organizations. The conceptual argument is offered on the basis of our empirical study. In this article we present a starting point for research projects that could advance the literature on intuition, such as expanding the notion of creative intuition. Furthermore, our findings can contribute to research on the development of expertise, and thus also to management learning more generally, primarily by emphasizing the significance of master-apprentice relationships and hot spots. Finally, our argument can also contribute to research policy development, particularly in the area of creativity and innovation management, by highlighting areas that should be supported both in terms of conducting creative and innovative projects as well as in educating junior staff.

Research in the natural sciences has a long history of providing an institutionalized international arena for recognizing outstanding research-for example, the Nobel Prize. It has had time to develop and consider how successful research is created, whereas management and organization research is comparatively young, and little consideration has been given to this topic (Johnson et al., 2006; Lee and Cassell, 2013; Thorpe et al., 2011).

With this as a context, we explore the implications of emergent properties identified from 19 interviews conducted with researchers recognized as excellent in areas other than MOR. Based on this enquiry, we suggest that we may be trying too hard to make MOR similar to some idolized and obsolete picture of science. It is possible that MOR is becoming more scientistic and by doing so becomes increasingly less scientific (von Hayek, 1942): "Science itself had to fight against concepts and ideas which were as injurious to its progress as the scientistic prejudice now threatens to become to the progress of the social studies." (p. 270).

In this article we focus on three themes emerging from our interviews: (1) the researchers' use of intuition in what the interviewees typically described as the "big leap" in the research process, (2) the role of the dual view of being able to cycle between the "big picture" and the detail, and (3) the role of research teams where the notion of the master-apprentice relationship is of particular significance. Examining these three themes, we identify discrepancies between what is reported in MOR and what we have identified as characteristics of excellent research as seen by our interviewees. Our intention is to explore what may be the possible issues in conducting and reporting MOR.

After outlining our research method, we discuss each of the three emergent themes and then examine the possible implications for MOR with respect to that particular theme. Finally, we present a synthesis of the implications in the form of a discussion rather than a conclusion.

\section{Methodological framework}

The research was designed as an empirical inquiry based upon conducting open-ended, loosely structured, in-depth interviews with individuals who are considered to be excellent in their respective fields. We decided to use this design because it would encourage richness of the data (Fontana and Frey, 1994) and so allow for emergent themes within the context of a reasonably broad research topic. In this approach "the object of the interview understood as being within a linguistically constituted and interpersonally negotiated social world, the qualitative research interview here becomes more objective than the methods of the natural sciences, which were developed for a nonhuman object domain" (Kvale, 1994: 153). Needless to say, such an approach 
brings difficulties of access, as in case of research on any elite (Gioia and Chittipeddi, 1991; Gioia and Thomas, 1996; Pettigrew, 1992).

Given our interest in excellent researchers, we decided to focus on those who were awarded the highest accolade of their respective fields with a presumption that they must, at a minimum, be in the top echelon of researchers. This does not imply that there are not excellent researchers beyond those receiving significant accolades - but rather that those who did win such accolades are likely to be exemplars of excellent researchers. Our interviewees (see Table 1 in Appendix 1) comprise Nobel Prize ${ }^{1}$ winners in Physics (8), Chemistry (3), Physiology or Medicine (1), and Economics (5), and two computer scientists who were awarded the "Eckert-Mauchly Award," which is often referred to as the Nobel equivalent in computer architecture. Furthermore, technically the "Nobel Memorial Prize in Economic Sciences" is also not a Nobel Prize, as often emphasized by noneconomists. When referring to all our interviewees, we call them expert scientists or "Nobel Laureates or Equivalents" (NLEs).

In order to enable collection of the richest data, we undertook prereading of the published works of the NLEs as well as using relatively unstructured interviews from the outset. Inevitably, the earlier interviews informed the later ones, meaning that the key concepts that emerged in earlier interviews were explored further in the subsequent interviews, although always after interviewees were given their own agenda.

We regarded simply analyzing the details of the large amount of text (transcripts, field notes, and the prereadings) as far too restrictive, although useful, in comparison with the actual experience of the interviews (exploring the nonverbals). Trying to preserve as much as possible of the richness of the above described interview process, we used designed conversations between the two researchers. A more detailed account of the research process can be found in Dörfler and Eden (2014); here, we provide a brief overview of how we worked. The focus of each researcher was deliberately different to increase rigor through a continuous questioning of the research activities. One of the researchers conducted all the interviews, after undertaking extensive reading of the interviewees' work and personal histories. The second researcher monitored the progression of the interviews and conducted interviews with the first researcher, typically 5 hours each, with the aim of exploring critical incidents as well as surprising and interesting interview experiences. This was followed by concept mapping workshops ${ }^{2}$ to facilitate, record, and identify emergent themes (Figure 1). The emergent themes were then transferred into a content analysis software, ${ }^{3}$ and the various texts (interview transcripts, field notes, and prereadings) were then coded against these themes (Figure 2).

As we tried to make sense of the interviews, supported by the field notes and in-depth exploration of the personal histories of the NLEs, we began the process of reflection and analysis on what we were hearing about the interviewed NLEs' approach to research. Comparing our experience in MOR with what we were hearing from the NLEs, three themes emerged in which the differences were most robustly observable. Once we had started identifying patterns of successful research as seen by our interviewees, we started theorizing about what we were seeing (Chia, 1996; Eisenhardt and Graebner, 2007; Weick, 1995b).

We discuss each of the three emergent themes of successful research, as seen through the eyes of these excellent researchers. Our findings are illustrated using indicative "power-quotes" from the interviews "where the informant is so poetic, concise, or insightful, that the author could not do a better job of making the same point" (Pratt, 2008: 501). In the article, we distinguish between two kinds of quotes: the power-quotes from the interviews are always block quotes, while the quotes from the literature are given in-text. The complexity of the identified patterns required us to engage with a wide range of literature from different disciplines. To cope with this situation, we do not 


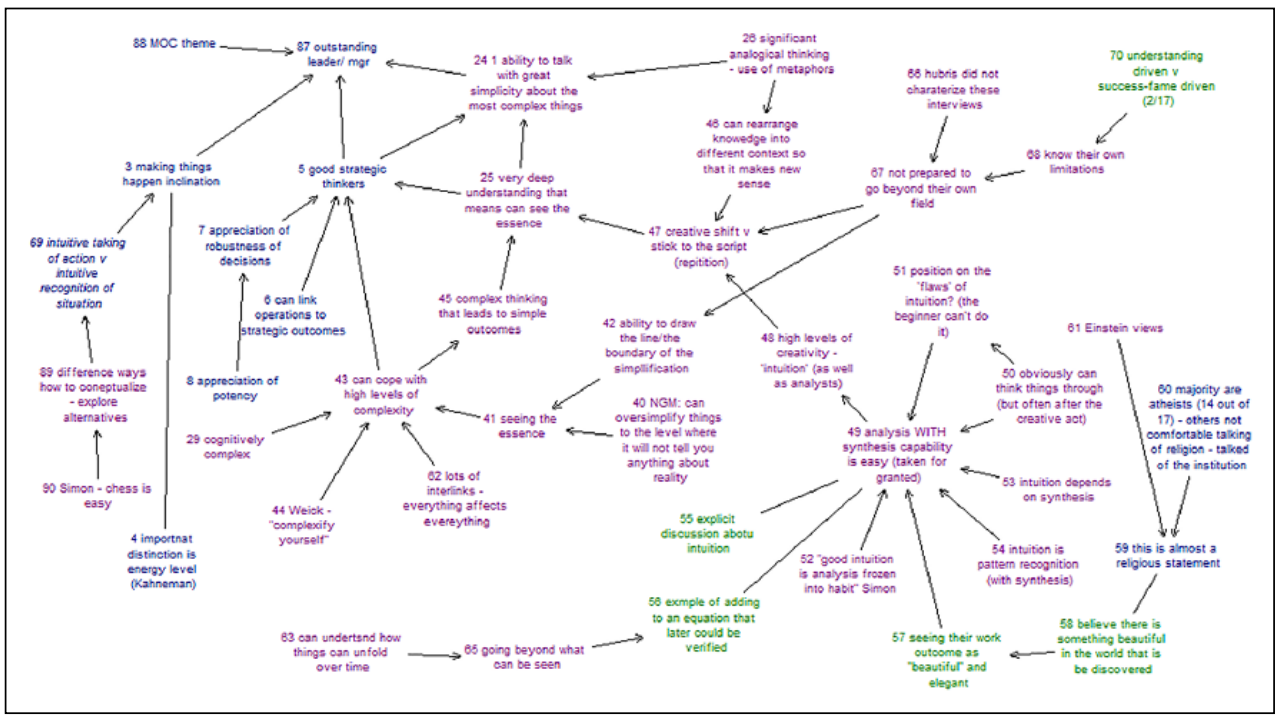

Figure I. One of the concept maps created during the analysis.

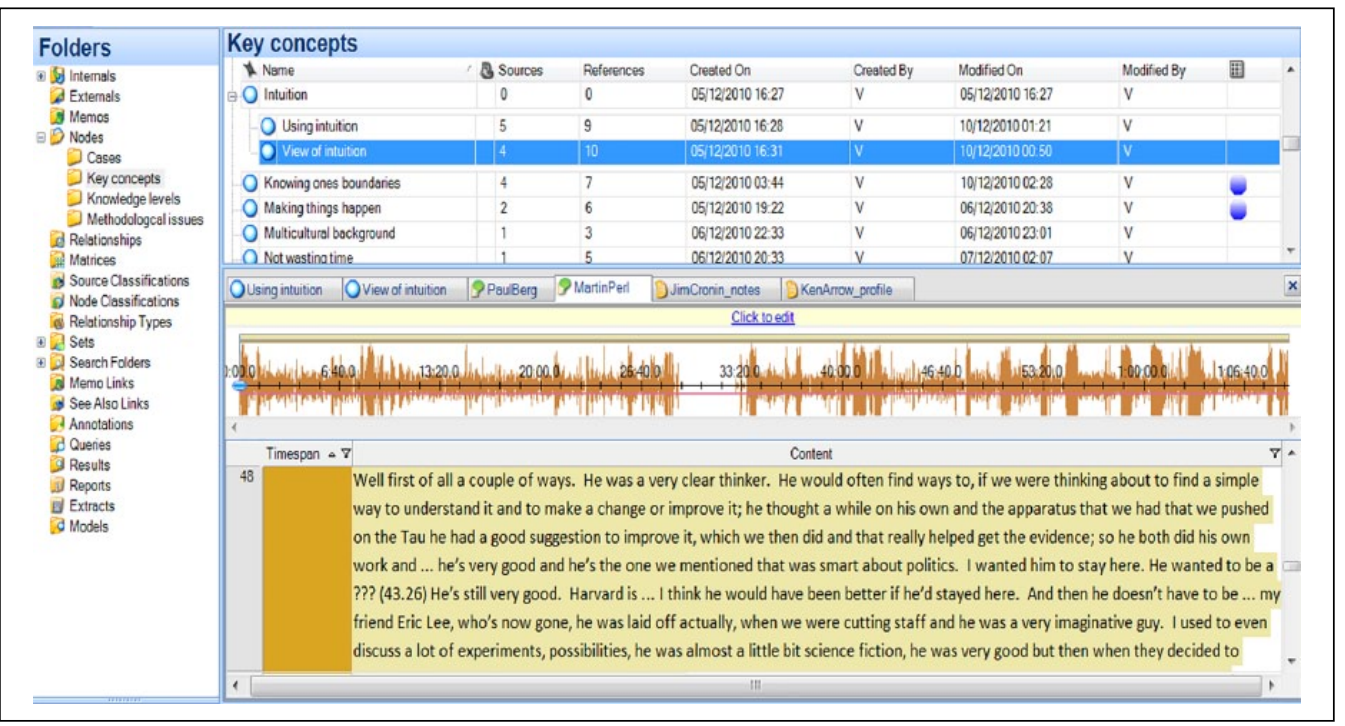

Figure 2. NVivo screenshot during the coding.

provide a traditional literature review at the start of the article, but rather provide three brief overviews of the relevant literatures (with indications of where more comprehensive reviews can be found) for the three emergent themes. We also draw on literature from the history and philosophy of science to provide additional context for the emergent themes. However, it is important to note that the use of literature followed our exploration of the data rather than to use it to frame our data analysis (cf. Gioia et al., 2013). 


\section{The role of intuition: making a leap}

Intuition isn't the enemy, but the ally, of reason. (John Kord Lagemann, 1910-1969)

The recent scholarly work in MOR describes intuition as "direct knowing" (Sinclair and Ashkanasy, 2005: 357); for summary and elaboration of the definitions, see, for example, Dane and Pratt (2007), Sadler-Smith (2008), Sinclair (2011), Akinci and Sadler-Smith (2012), and Dörfler and Stierand (2017). In this article, we use a conceptualization of intuitive insight congruent with Dörfler and Ackermann (2012).

Simon (1987) describes intuition as "analyses frozen into habit" (p. 63), and Weick (1995a) suggests "condensed expertise" (p. 88). Davenport and Prusak (2000) suggest that

[t]hose with knowledge see known patterns in new situations and can respond appropriately. They don't have to build an answer from scratch every time. So, knowledge offers speed; it allows its possessors to deal with situations quickly, even some very complex ones [...] We arrive at an answer intuitively, without knowing how we got there. (p. 11).

Models of the development of expertise emphasize that "intuition" becomes more and more dominant with the increase of expertise (e.g. Dörfler et al., 2009; Dreyfus and Dreyfus, 1986; Simon, 1996), and Kahneman and Klein (2009) suggest that only experts' intuition is reliable.

This observed significance of intuition in research is consistent with Popper's view that "every discovery contains 'an irrational element,' or 'a creative intuition,' in Bergson's sense." (Popper, 1968: 8, Popper's use of "irrational," should be interpreted as "arational.") Similarly, Bergson (1946) stresses that no complex thought can be arrived at other than by means of intuiting. Consistent with this, for our NLEs, no significant research result seems to have been achieved without intuition playing a major role in the process. Notably, we found no counter examples where a NLE did not admit to using a form of "intuition" or did not provide examples of intuition being used.

Klag and Langley (2013) describe the unexplainable magic in making conceptual leaps, which very much resembles how NLEs described their experiences. For example, James Cronin (NL in Physics 1980), when talking about how much he based his scientific problem-solving on intuition, said,

I don't know if intuition or . . you build up over the years of experience, and you kind of have a sense of what's going to work and what's not going to work.

Similarly, Yoichiro Nambu (NL in Physics 2008) described intuition as a kind of intellectual feeling,

Something that's clicked in my mind, that seems interesting or something that's maybe promising that's a kind of feeling I have.

Daniel Kahneman (NL in Economics 2002) quotes his wife describing his intuitive thinking,

I mean, you know, where I've been successful is in seeing very simple patterns in complicated situations. So, I'm good at that, and my wife [Ann Treisman] says I see patterns in clouds [ . . .]

Similarly, 
I have this experience many times when I'm working intensely on some problem and then discussing it with a collaborator or a student and suddenly I say something and then I say 'that's an interesting idea' [. . . ] It just comes out and I have no idea from where. I mean, I'm saying it but . . . (David Gross, NL in Physics 2004)

. . . for instance, the idea of going into ultra-low temperature physics because I just felt that the technology we were going to find some new stuff. I guess at some level that's intuitional. (Douglas Osheroff, NL in Physics 1996)

Those of our interviewees who did not use the term intuition described their work in terms similar to those used in the MOR literature on intuition, such as "condensed expertise" or "just knowing" (further examples can be seen above).

\section{So what for management and organization research?}

Our research with NLEs, together with examples from the history and philosophy of science substantiate the role of intuition in making leaps in research (cf. Klag and Langley, 2013). Corley and Gioia (2011) have made a plea for more "initially surprising theories" (p. 16-17) in MOR (cf. Mintzberg, 2005) that radically change perception, and they note that "current thinking at AMR and other top research outlets seems to have shifted to a focus on theoretical contributions deemed to be more revelatory and nonobvious [as opposed to incremental] to organizational scholars." For such nonincremental, radical, and surprising theories, intuition may be indispensable. Intuition as a "big leap" is one way of providing frame-breaking insights that is a key criterion of good theory besides testing (e.g. parsimony, logical coherence) and convincing grounding in the evidence (Eisenhardt, 1989: 532). Similarly, intuition as a "big leap" can help advance theories that are capable of closing/ narrowing "the gap between forward living and backward understanding" (Weick, 1999: 138).

However, Polányi (1962b) notes that the traditional conception of "objective sciences" "would be shattered if the intuition of rationality in nature had to be acknowledged as a justifiable and indeed essential part of scientific theory" (p. 16). As Tsoukas (2005a: 142) argues, researchers mistrust intuitive knowledge obtained through ad hoc or, at least, less-defined practices. In Einstein's words (quoted by Klein, 2004: 3): "The intuitive mind is a sacred gift and the rational mind is a faithful servant. We have created a society that honors the servant and has forgotten the gift." Perhaps in MOR, the role of intuition is undervalued in prosecuting good research, or, at least, researchers are not prepared to openly discuss its role.

Of course, there is a need for much nonintuitive thinking that prepares the stage for intuition and also converts the intuitively obtained solution into publishable research findings (Bergson, 1946; Hadamard, 1954; Poincaré, 1914). Our research suggests that although NLEs do not use intuition all the time or in every situation, their successful research is always advanced by a form of intuiting. With regard to such successful research, our data supports the Bergsonian (1911: 238-239) view of the importance of going back and forth between intuition and analysis. It appears that intuition is more likely to yield one of those "big ideas" which "runs ahead of existing empirical research"; however, these ideas then "require nurturing, development, and revision" (Kilduff, 2006: 252). Here, intuition helps researchers arrive at new ideas, after which intuition is abandoned and researchers work on building the body of knowledge using the new intuitively obtained knowledge. Then, once they start feeling lost, researchers should get in touch with their intuition again (often undoing what has been done in the analytical phase) and so forth in cycles (Bergson, 1946).

When reporting on our findings, and the methodological approach and methods employed, the MOR community does not admit to a role for intuition. If we assume that management and 
organization researchers have some similarity to researchers in other fields, we might assume that the intuition-analysis cycle is present in successful MOR as well. However, this is virtually never acknowledged explicitly in publications, presentations, or our teaching about how to do research. Perhaps there is a fear that it could be seen as improper by our peers. We do not suggest that research papers in hard sciences are full of references to the intuition of the researcher; we only suggest that in hard sciences researchers do not hide its role. The reason may be that if intuitively obtained insights need to be justified in, for example, physics or chemistry, it can be expected that the analytical explanation is completely rigorous; simply it is sufficient "that their results seem to "work" (Phillips, 1973: 154). In contrast, "management theories are more complex and, hence, more difficult to structure in a way that is scientifically testable with any degree of clarity" (Devinney and Siegel, 2012: 6), and therefore "it is enormously difficult to evaluate the results of various inquiries" (Phillips, 1973) and this may be another reason for not admitting intuition. In any event, we may be discouraging the potential for a "big leap" in MOR by not admitting it either in practice or in reporting our research.

What might be done to change this situation? First of all, an environment in MOR would be required where the role of intuition is as admitted to be potentially important (Agor, 1984b; Sadler-Smith and Shefy, 2004: C5). In hard sciences, labeling a researcher as "intuitive" means a great deal of respect: "The warm praise that scientists lavish on those of their colleagues who earn the label 'intuitive' is a major evidence that intuition is a valuable commodity in science . .." (Bruner, 1977: 67). Such an environment would mean that the intuitionists do not feel that they should hide it and pretend that their results have been achieved otherwise. Beyond legitimacy, a changed environment can support greater receptiveness for a researcher of their own intuition as well as acting upon, reflecting on, and discussing intuitive experiences with peers (Agor, 1984a: 66). In our management and organization doctoral courses there would be a need to discuss the potentially powerful role of intuition once the researcher becomes an expert. Perhaps management and organization researchers also need to be less sensitive to accusations that using intuition is against scientific rigor.

As we have seen, intuition, as a form of tacit knowledge is always partly obtained through apparently ad hoc or, at least, less-defined practices. The double-blind reviewing system means that it is usually not possible to know whether it is the work of an "expert" intuitionist that is surfacing. This means that for results where intuition has played a role, the convenience of simply checking whether the steps of a method are adequately applied would not be the only test. Those judging the work in which intuition was assigned a significant role would have to judge whether the outcome makes sense. This could work on the basis of what Polányi (1966) calls "the principle of mutual control" (p. 72), that is, the findings could be intersubjectively tested (Popper, 1968: 22). As the scholars" "personal fields will form chains of overlapping neighborhoods extending over the entire range of science" (Polányi, 1966), it would, in principle, be possible to get appropriate judges of creative outcomes (Amabile, 1982: $1001 \mathrm{ff}, 1983: 359$ ).

\section{Holism and detail: seeing "the essence"}

Things may have a real essence . . but this is in the main unknown to us, and is not the "essence" of which scholastics speak. (Bertrand Russell, 1872-1970)

When we talk about "seeing the essence," we usually mean that the person who is good at seeing the essence is able to decide which one of the available details is significant from a particular point of view. Cognitive psychology provides some explanation of this when they describe the phenomenon of "chunking" (Gobet and Simon, 1996a, 2000; Simon, 1974). When considering the 
relationship between the "big picture" and the detail, there is a need to make a connection to the hermeneutic circle - Gadamer's (1975) view, which is focused on the interpretation, rather than Heidegger's (1927/1996), which was conceptualized ontologically, clarifying the relationship between the phenomenon and its context. Practicing the hermeneutic circle can be regarded as a way to improve seeing the essence.

It sounds almost trivial to discover that expert scientists can "see the big picture"able to demonstrate a holistic grasp of their topic. The notion of "big picture" does not refer to size but to wholeness. What matters is that, whatever the theme of the "big picture" is, it is considered as a whole, and that this "big picture" also serves as a framework for making sense of the detail, and vice versa. It is also perhaps obvious that these people have good sense for the "essence" of the research problems they face (Craft et al., 2008; Ericsson, 1996; Gobet and Simon, 1996b). These conventional wisdoms are confirmed by our research, and unpacking them helps getting a better grip on what the essence is.

However, and perhaps more importantly, we see as particularly noteworthy the ability of NLEs to not only see the "big picture," to detect holistic patterns in the data but also to get into the detail and validate or elaborate their holistic view. NLEs also demonstrated the almost simultaneous ability to see what details and combination of details affect the pattern in what ways and which details may change the "big picture." Significantly, NLEs seem to be able to switch between the "big picture" and the detail at incredible speed, and they do it frequently and with ease. That is also how they can revise or revalidate their "big picture." These are aspects of seeing "the essence" - that is, the detail that is relevant here and now. We can, however, develop a richer picture about the essence by examining this notion in the framework of sensemaking (Weick, 1979, 1995a).

NLEs can see the whole and so will be able to extract a cue that represents the whole together with the context. In this sense, "the essence" is the special cue that NLEs see as they are able to see the whole, and extract this special cue that is somehow the condensed version of the whole, and yet also know and use the detail. The phenomenon of the "big picture and detail" cannot be illustrated purely with direct quotes from the interviews, as our interviewees were not talking about it, but rather demonstrated it during the interviews, in their writing and talks. For instance, Martin Perl (NL in Physics 1995) started in his keynote talk about his recent research on "dark energy" (Perl, 2009) by saying that we do not know much about "dark energy," but we do know that

it is certainly not dark and it may not be energy at all.

This is a good example of understanding that the characteristics usually associated with the phenomenon are unimportant and shows a sensing of the essence that he cannot start formulating.

In the interviews, seeing the essence enabled the NLEs to change the "big picture" forming in the mind of the interviewer, by changing or emphasizing a particular detail. For example, Roy Glauber (NL in Physics 2005) offered a powerful yet simple explanation of the often-noted beauty of the Maxwell equations:

You could look at those equations and you won't see. You must understand what the nature of the transformation is and then you will see it. But that requires a slightly different mathematical formulation.

$[\ldots]$

Those six independent numbers that specify the anti-symmetric matrix are components of the electric and magnetic fields, and that wouldn't be at all obvious to you in looking at the usual three dimensional equations. But in this four dimensional context it suddenly has a beautiful simplicity to it. 
When discovering the Tau Lepton, Martin Perl made a "big leap" by recognizing a detail that confused everyone else, that is there can be a particle which is almost identical to an electron, only 3,000 times heavier. This changed the "big picture" of elementary particles.

Michael Flynn (Eckert-Mauchly Award 1992) discussed his idea of a computer that could be printed on a paper and used as a newspaper, in relation to "artificial fruit flies" (tiny computer devices that can fly around the room using their sensors) he was building, using the same detailenergy as a bottleneck - in two very different "big pictures,"

You could do print-on-paper computers, because there is actually special ink which can store electricity, so you can make batteries out of printed ink [. . . ] Now, you could print displays, you could do these, if the power was low enough. Everything is very sensitive to power and the way you do energy, is a better way of saying it, because a newspaper, for example is only valid for a few days or something, so as long as the energy was able to sustain the visibility or the computation for a couple of days, then you throw it away.

Similar instantaneous switches between the detail and the "big picture" are not uncommon in the public talks, media interviews, and writings of the NLEs.

\section{So what for management and organization research?}

In MOR, the focus is typically on the snapshot rather than context over time. Devinney and Siegel (2012) go as far as asserting that "the vast majority of research studies in management are one-time efforts because access to the data is limited" (p. 7). The pressures to get published might be leading MOR researchers to collect data too quickly and process the quickly collected data using simple and often inappropriate statistical tests (Cumming, 2014). Such pressures can often restrict our understanding of the "big picture," which would take time, as the socio-material, spatiotemporal context is poorly understood. A "big picture" research program would take more time and so inevitably imply small sample size conclusions, including $n=1$, and so take away the usual methods for establishing statistical robustness, and so make it more difficult to publish. Ignoring the wider characteristics important to the research problem because they are difficult, means precluding the possibility to see holistic patterns. The narrowness of data means that the focus is on the detail and a small part of the detail, which possibly leads to missing "the essence."

For understanding the "big picture" in MOR, we need to understand the temporality-exploring, understanding, and describing process and change in context over time (Eriksson and Kovalainen, 2008: 27; Gummesson, 2006; Tsoukas and Chia, 2002). And yet MOR projects study snapshots at a point in time. Using Pettigrew's (1997) words,

Metaphorically we are studying some feature of organizational life not as if it represents one stream in one terrain, but more like a river basin where there may be several streams all flowing into one another, dependent on one another for their life force and shaping and being shaped by varieties of terrain each constraining and enabling in different intensities and ways. (p. 340)

Similarly, the emphasis on the need for replication means concentrating on a narrow type of data that can be recorded and replicated without interference from the changed context. For example, even in collecting snapshot data crucial nonverbal material is often ignored, and yet this data is generally acknowledged to account for two-thirds of the data in an interview. So, interview data gradually moves from studying the experience (including verbals, nonverbals, context, and setting) to that which can be collected in an audio file and onward to that which can be transcribed 
and content-analyzed. Even though some acknowledge the interview experience itself as a rich source of data, nonverbal data is rarely mentioned. Even though understanding the context is clearly important, field notes and impressions are underutilized (Riley et al., 2000: 129-132). This research practice holds even though most of us in MOR acknowledge, for example, that "non-verbal communication is just as important as the language practices. It includes body language, facial expressions, how people choose to arrange themselves in a room for a group session, customary and accepted ways of greeting one another. All of this contributes to your analysis of the observation materials" (Eriksson and Kovalainen, 2008: 86-93). So, it seems that MOR could be absorbing more from the practice of good anthropology (such as Appadurai, 1990; Ingold, 2011; Mead, 1959).

This all means that MOR typically concentrates on the detail while neglecting the "big picture." This is not to say that there are no researchers who focus on an understanding of the "big picture," for example, Karl Weick's (1979) Social Psychology of Organizing and Pettigrew's (1985) The Awakening Giant are each different examples of seeking to capture and explore the "big picture." However, talking about the "big picture" is difficult in journal publications and particularly so in reports of empirical studies. Any "big picture" comments are usually relegated to the introduction and/or discussion sections of articles and occasionally found in conceptual articles. Predominantly, however, "big picture" articles, rather than books, are published almost exclusively by a small number of leading scholars in editorials and invited opinion papers.

As in the case of intuition, the duality of the "big picture" and the detail can be advantageous, particularly when focusing on emergent properties.

The importance, for the NLEs, of seeing both the "big picture" and the details, as well as an ability to switch between them, is not limited to collecting and analyzing the data; it also affects theorizing. In MOR, Tsoukas argues that "we badly need complex theories which will take into account context, time, history, process, meaning, politics, emergence, contingency, feedback, novelty, change" and this leads us to chaos and complexity theories (2005a: 224). Therefore, to foster "seeing the essence" means frontally addressing what March (2008) identified as the main problem of MOR: that it is the "essence" rather than the "relevance" that is missing. We take this to mean that the results of scholarly research may not be entirely irrelevant to practicing managers, but they will fail to make a difference.

\section{Building and developing research teams: "hot spots"}

A theatre cannot work with all the actors being Laurence Oliviers-but it is noticeable if there is none. Zoltán Baracskai (1953-present)

All the interviewed expert scientists discussed their experiences of being a part of a research team. The excellent research of our interviewees was not a solitary activity. Two related themes were particularly forceful: (1) the significance of what is generally referred to as "the master-apprentice model" is apparent in our data and (2) the development of research "hot spots." In this section, we present our findings with respect to these two aspects of development of research teams.

\section{The master-apprentice model}

The master-apprentice model of teaching-learning can be traced back at least to the medieval workshops of arts and craftsmanship, but it is not a stretch of imagination to go back to Socrates walking with his disciples at the Agora or to the priests of ancient Egypt. While historically the master-apprentice relationship has been recognized as a highly effective way of transferring 
expertise of high complexity, and it has often been suggested that it may be the only way of passing on tacit knowledge (Polányi, 1962a, 1962b; Stierand, 2015; Tsoukas, 2005b), it is not easy to find examples of it in today's world of business and academia. The primary reason for this may be the highly asymmetric nature of the master-apprentice relationship. However, this asymmetry has been of great importance to the development of the NLEs. It is important to emphasize that in spite of all the inequalities, some of which are examined below, the master is not more important than the apprentice. For the master-apprentice relationship, both are necessary.

The traditional master-apprentice relationship describes a close working relationship of a "master" and of an "apprentice" (or disciple), where there is a great difference in expertise at the beginning of the process. This model follows the traditional setup in the workshop of a craftsman or artist. If the apprentice is a novice at the start of this process, it is expected to take around 10 years to achieve the highest level of expertise, if, and only if, the apprentice has the talent to achieve the highest level of expertise in that discipline in that professional-social context. This time period maps on to the well-known "10-year rule" (which corresponds to around 10,000 hours of invested effort during this time), originally suggested by Simon and Chase (1973) on the basis of observing chess players and later confirmed by others in a variety of contexts (e.g. Ericsson, 1996; Ericsson and Charness, 1994; Ericsson and Crutcher, 1990; Ericsson et al., 1993). It appears on the basis of the findings from such a wide variety of knowledge domains that the length of the master-apprentice relationship is not a matter of choice, but rather the consequence of the nature of the development of expertise. Frequently, the apprentices joined their masters somewhat later in the process of their professional development (e.g. in academia, after undergraduate and possible master's studies), and for our NLEs, around 6 years of such relationship was regarded as necessary.

The role of the master was not without difficult social issues. There is one particular aspect of the relationship, which is directly important for the development of the apprentices, where the master has to tell the disciple if (s)he is not sufficiently talented for progressing further in the discipline and so must be removed from the team. It is easy to tell someone that they are talented and that it is worth working hard as they are expected to develop into excellent researchers, but our NLEs found it hard to tell someone that they should give it up as they are not talented enough to become outstanding researchers by working with them. Yale Patt (Eckert-Mauchly Award 1996) told the story of the only case when he hesitantly agreed to take on an apprentice in spite of his negative feelings about doing so, as the disciple was very enthusiastic and "ticked all the boxes"and yet he still feels guilty because it did not work out for either of them, and the enthusiastic disciple wasted a year of his life. Since then, Yale Patt does not hesitate to advise disciples or applicants to find a different discipline or a different master based simply on

a feeling for whether or not we're on the same wavelength, whether the chemistry is right . . .

This example emphasizes that talent is not only about the discipline but also about working and learning in a particular workshop, with a particular master. In other words, talent is socially constructed in two ways. On one hand, as talent relates to a discipline, it is constructed and acquired with reference to that discipline, which is socially constructed. On the other hand, this construction and learning take place within a particular workshop, under the care of a particular master. Therefore, it is possible that someone who is not able to become a great physicist as member of one research team could achieve this in a different team.

The asymmetry of the master-apprentice relationship does not end with the difference in expertise. The god-like figure of the master imposes itself upon the apprentice, and the master sometimes gives orders without explanation. This will be at a particular stage of development in the 
research where it is difficult to explain, for example, when the master follows his or her intuition. Kenneth Arrow told us a story about his master, Harold Hotelling, that offers little explanation to a young disciple,

I was in his office [. . .] and he said "I'll be very glad to nominate you for a student membership in the Econometric Society" which I took to be a command - correctly.

However, explanation is often simply not readily available, as the advice is based on the master's intuition; Kenneth Arrow explains this in the example of telling his apprentices that an avenue of research they want to pursue is not promising,

[. . .] obviously my job is to tell them . . I can see this isn't going to work, either because somebody else has done it or because I can just see it doesn't work.

We found numerous examples of the traditional master-apprentice relationship in our interviews with the NLEs, where the current NLE was the apprentice and where he was the master. There was one master-apprentice relationship between Robert Lucas (NL in Economics 1995) and Edward Prescott (NL in Economics 2004), where both the master and the apprentice were our interviewees. Robert Lucas told of one of his favorite apprentices,

Edward Prescott, who got a Nobel prize in economics a few years ago, was a student of mine [. . .] And I started out working jointly with Ed Prescott, and then we did some nice work together, and then we sort of broke up [. . .] he took some paths that I wouldn't have walked down with him [ . . . I like the work he did, it was good for him and good for me too. I mean, so the apprenticeship thing in some sense worked well [. . . ] I don't think these things should be like marriages that go on forever.

And Edward Prescott fondly remembers his former master,

Of course Lucas is the Sir Isaac Newton of the profession. He's in a different class [. . .] He's a damn good, superb mathematician too. He was so far ahead of everybody else, this vision of using dynamic economic theory to study ... .

In a separate article (Dörfler and Eden, 2017), we explore the role of the master-apprentice relationship and its different forms. What we have seen so far seems to suggest that the highest level of expertise cannot be achieved without going through some form of master-apprentice relationship (cf Polányi, 1962a, 1962b).

\section{The significance of "Hot Spots"}

Another key emerging theme from our data was the significance of "hot spots." Roy Glauber posed an interesting question during his interview,

You have, in China, an astronomical number of scholarly people and many of them brilliant, and quite a few of them very well informed. They know what we're doing. They're reading all the papers, why has so little of this material come from China in modern times? The answer is it happens in "hot spots".

This was not the first mention of "hot spots" we came across. Gradually the role of "hot spots" emerged as being of particular importance. The first such description came from James Cronin: 
I was lucky enough to come to Chicago and I had some good teachers. Not only Enrico Fermi but Val Telegdi, a Hungarian colleague of yours who is, sadly, no longer alive, and Murray Gell-Mann, Marvin Goldberger. So the teaching and passion of the students at Chicago were exceptional, so, I imagine, that had something to do with it, but I was just in the milieu which was just right. (our emphasis)

An interesting example of how "hot spots" work came from the biochemistry lab at Stanford, which is the purest archetype of "hot spot" described in our interviews. It was founded by Arthur Kornberg (NL in Physiology or Medicine 1959) and described to us by Paul Berg (NL in Chemistry 1980). Each "hot spot" has a continuous workshop environment that was, in the cases we know of, originally founded by one single master, sometimes helped by senior apprentices:

. . . and then Kornberg was asked to come to Stanford to start a new biochemistry department here but what happened is the seven people he had assembled in St Louis we all moved together. (our emphasis)

It seems to be important for a "hot spot" to occur that there should be one single person as a dominant figure with a strong line of senior apprentices behind them, as this makes a coherent culture (value system) possible. This value system will be so strong even in a "more democratic" period, that latercomers will only be able to fit in if their value system is also compatible (cf Nakamura et al., 2009).

In some instances the working of a "hot spot" is extreme. In Kornberg's biochemistry lab, the former senior apprentices are not only colleagues but also best friends; they are next-door neighbors (they live on the campus), their children (and later grandchildren) played together, and they have lunch together every day. This has not changed in the last 50 years. Everyone at the lab is pursuing independent lines of research, but they operate an extreme, perhaps unprecedented, openness of research ideas and results where these are discussed at lunch and made available to anyone interested within the lab. It often happens that a half-baked result finds a use outside the originally intended line of thinking and in a different research group. So the working of the lab is deeply trust based and highly professional but also depends on close personal relationships. For example, as Paul Berg said,

So it's been a very unusual, and not easily reproducible I'm sure, but the idea of reproducibility is I think it's easy if you don't have the sense of ownership. [If] my value, or standing depends on how many square feet I have, or how many people I have in my lab, OK? If you live that life you can't live the way we do. We gave up that kind of individuality in saying 'I don't care where my students and post docs are.' I'll go to them and talk to them, and we have weekly meetings. But . . . it's very likely that one of my students will say 'did you know what happened in the other lab?' So we've got a lot of diffusion, very rapid diffusion of information and techniques and skills, reagents, all that kind of stuff.

A very significant level of trust and very stable value system appears to be needed for any "hot spot" to operate over a long period of time. It is the lab or workshop that can be identified as a "hot spot," but it is the people who constitute it. This means that the "hot spot" is not only a place where apprenticeship happens but also a place that genuinely facilitates originality and high-quality research. Such places are characterized by openness of research where ideas and results are discussed at lunch in trust-based highly professional relationships and where close personal relationships were important, particularly because they open up the possibility of a "heedful collective mind" developing (Weick and Roberts, 1993).

\section{So what for management and organization research?}

The existence of "hot spots" has possibly decreased in our field over the past 50 years. In the United States, the workshop formed around Herbert Simon (Augier and March, 2004; Spender, 
2013) at Carnegie Mellon mostly disappeared; Peter Drucker's (druckerforum.org) disciples tried to keep alive the workshop in Claremont, but it is more of an "In Memoriam" today; and Jay Forrester's $(1958,1994)$ system dynamics group is reduced to John Sterman (the MIT System Dynamics Group is a broken link). At the time we wrote this article, there was still some activity around James March (March, 1994; March and Simon, 1993), but he recently died, and Karl Weick $(1979,1995 \mathrm{a})$ has been seeing decreasing significance, as he moves to full retirement. In the UK, research groups such as the "Aston Group" around Derek Pugh (Clark, 1997; Pugh et al., 1968, 1969), the group at Warwick around Andrew Pettigrew (1990, 1992, 1997), and the original Industrial Relations group at Warwick (Clegg, 1970; Flanders, 1970) have largely disappeared.

In MOR, similar to researchers in other fields, we have a desire to distinguish science from pseudo-science (Kilduff et al., 2011), that is, where "all members of a scientific community are assured a kind of collective protection: madmen, charlatans, fakers and sophists are hopefully excluded from the ranks." (Phillips, 1973: 154) This desire is being achieved by two means: hanging on to a so-called scientific method and developing a highly encrypted professional language that only the insiders can understand. It seems that the means defeat the desire, and so, the researchers have become isolated from those who could put our newly created knowledge to use. As Prusak (2004) comments, "You people write for journals you only read." Beyond this more apparent problem, however, the community of scholarship in MOR seems to evaluate the value of a contribution "using methods that privilege technique over substance and method over an understanding of the complexities of the field in which we work" (Cunliffe and Sadler-Smith, 2014: 3). Furthermore, it is possible that skillfully presenting research results has become more important than creating new knowledge and, consequently, there are articles in highly ranked journals that do not significantly advance the domain knowledge (cf excellence vs playing the publication game in Butler and Spoelstra, 2012). In MOR, we repeatedly hear from our most respected scholars, who did produce significant new knowledge, that with the current system in place they would have never developed into the researchers they are recognized to be today (e.g. see Thorpe et al., 2011: 429). The adherence to "the method" may have a similarly detrimental effect on producing great research, as "while method may have a unifying effect and provide a kind of collective protection for a discipline's practitioners, it restricts the freedom of the individual scientist" (Phillips, 1973: 151). It may be necessary that researchers free themselves from the chains of methods if they are to achieve breakthrough results (Feyerabend, 1987, 1993).

In the United States, the demands of the tenure track process encourage single-authored articles and individualism in research and publication. In the United Kingdom, the Research Excellence Framework is discouraging collaborative research and publications from research teams where team members "live together" by disincentivizing the submission of joint authorship of articles from people in the same institution.

Perhaps the strongest implication, therefore, is to encourage the deliberate provision of greater incentives for the creation of research groups and "hot spots" in business schools. The significance of the apprenticeship model suggests, for business schools, perhaps a greater emphasis on the involvement of doctoral students within experienced research teams - more akin to the engineering model, which reinforces the need to create more "hot spots" of research teams.

\section{Discussion}

In this article, we reported findings from interviews with expert scientists from a range of disciplines. Nobel Laureates and Equivalents were used as exemplars of excellent researchers, not denying that there are excellent researchers beyond this group, and not aiming for a comparison between excellent and less excellent researchers; rather we were interested in how these excellent 
researchers talk about their research process. The three themes examined in this article emerged naturally as we sought to make sense of our interviews and the contextual material. The emerging themes of (1) using intuition in "big leap," (2) seeing the "essence," and (3) researchers developing through master-apprentice relationship and in "hot spots" are not only of interest for the development of excellent research in general but that they also may have some implications for developing more successful MOR.

Therefore, our contribution primarily extends the rigor-relevance debate in MOR by offering a viewpoint worthy of consideration. Our analysis can provide the foundations for a critique of how we do research and produce knowledge about management. In addition, we provide empirical contribution-based theorizing to the literature on intuition as well as on the development of expertise. Furthermore, our findings are relevant to management learning more generally as well as for research policy, particularly in creativity and innovation management.

The essence of our argument stems from the observation that in the field of MOR we seek perhaps to adhere to an idealized view of the scientific method that is distorted and outdated. As a consequence, we may be making MOR more scientistic rather than more scientific (similar arguments have been put forward, e.g. by Hodgkinson and Healey, 2008; Pandza and Thorpe, 2010; van Aken, 2005). Furthermore, our research findings might be seen to encourage action research, which is not only contextualized in the lifeworld of the organization and longitudinal allowing for observation of processes and emergences but also deals with taking action based on what the researchers see implementing it and observing the consequences. (Eden and Huxham, 1996, 2006; Hillon and Boje, 2007; McInnes et al., 2007)

At the end of each section (under the heading of "So What for Management and Organization Research?"), we have speculated on what the implications for management and organization researchers might be. We summarize these implications here and further explore their synthesis:

- Intuition: In the MOR community, we need to accept and encourage a role for intuition as a legitimate part of developing contributions to knowledge, without compromising a commitment to rigor. Importantly, we do not argue for intuition alone, but rather for an intuitionanalysis cycle.

- Attention to both holism and detail: Develop skills in researchers to see the "big picture" and yet also get into the detail swiftly, frequently, and easily. Switching between the "big picture" and the detailed view is about being able to see "the essence." Taking a stronger interest in process and flow and the wider context and accepting that much significant MOR inevitably cannot follow the "controlled experiment" approach and must, by its nature, be more idiographic.

- Developing research teams: Provide incentives for the development of master-apprentice teams that are colocated. Create the circumstances for the virtuous cycles necessary for the creation of "hot spots." Recognize and encourage collaborations that may enable the germination and growth of "hot spots."

There are many ways that the three identified themes intertwine; these are in the form of dualities which, starting from a tension, through cyclical responses, produce a dynamic equilibrium, similar to the paradoxes examined by Smith and Lewis (2011). First of all, each of the themes can be described as a duality of opposites that complement each other in a dynamic interaction. Intuition and analysis follow each other in cycles as "big leap" and small steps. Focusing on the "big picture" and then on the detail and cyclically shifting this focus back and forth leads to meaningful research outcome. The two subthemes of the research team development each have their own duality. The apprentices, at least the best ones, will become masters and have their own apprentices. In 
the "hot spot," we have the duality of the individual and the team in a dynamic balance, where neither is neglected. So, each of the emergent themes are dynamic dyadic entities in themselves, and they are also intertwined and interacting. Interestingly, the first theme focuses on method/ process - legitimacy of intuition, which is linked to the ability of the researcher-ability to cycle between abstraction, patterns, "helicopter view," and ability to work with detail, and the third theme relates to resourcing - creating "hot spots."

Intuition is related to the dual view of the "big picture" and the detail in terms of their usefulness in research. It is easier to develop intuiting in a master-apprentice relationship, and the dual view is also often acquired in apprenticeship. A "hot spot" also seems to be the place where both of these themes can be practiced, improved, reflected upon and, perhaps most importantly, receive meaningful feedback for. It is expected that a "hot spot" would be the natural context of the masterapprentice relationship, and it seems plausible that the master-apprentice relationship is a precondition of developing a "hot spot."

Historically, the area of MOR is a latecomer to the scientific enterprise. As Corley and Gioia (2011) explain, business schools "began to emphasize more rigorous, quantitative orientations in an attempt to gain legitimacy within the larger academic community [. . .] this helped move our field away from the criticism that management and organization knowledge was mainly a collection of anecdotes" (p. 15). In an attempt to develop a more systematic approach to research in MOR, we have perhaps lost sight of the potential for creating interesting theories. "A theorist is considered great, not because his or her theories are [necessarily] true, but because they are interesting" (Davis, 1971: 309 quoted in Corley and Gioia, 2011: 17). Few would argue that NLEs are not systematic about making their contribution to knowledge, but they do allow for intuition and have the ability to move between the "big picture" and detail. If we are to take seriously the demands for interesting and surprising theories in MOR, then perhaps we need to pay more attention to the ways in which NLEs attain a "big leap." It is, therefore, important to learn the use of intuition, seeing the essence, and also strive to develop the new generation of researchers in "hot spots."

There are several limitations to this research. First, to some extent, we may be guilty of what we are arguing against-scientizing our findings. However, it is interesting to note that our approach to our data was not driven by our need to see the emergent themes-either from a literature perspective or our preconceptions. Rather, as it turned out, we followed a process somewhat similar to that discussed by our sample of NLEs - cycling between intuiting and analyzing and from holistic patterns of the "big picture" to detailed formal analysis.

It is reasonable to ask why we have not sought to make comparisons between our so-called extraordinary researchers and those who might be defined as mediocre or poor scientists. Our project was aimed at exploring the views of excellent researchers - a category that is easily recognizable when addressing NLEs. As we argued earlier, it is likely that the category of excellent researchers goes beyond the NLEs, and there are likely to be equivalents in the field of MOR. However, because NLEs are typically regarded as excellent researchers, our objective was to discover something of their approach as they saw it. It seemed to us that such a study must be of interest to researchers in our own field given, as we have suggested, our field is young and we have demonstrated a wish to be seen as scientists.

Our interviewees are from the disciplines of medicine, chemistry, physics, computer science, and economics; thus, there is a disciplinary leap to MOR. We do not see any reason to believe that the disciplines of the interviewees are likely to be more similar to each other than they are to MOR. However, we do assume similarity of researchers and of the nature of research work. There is also a time leap, as the highest awards in any discipline are typically awarded years, often decades, after the award-winning achievement. We addressed this limitation by including lessons from the history and philosophy of science, which we believe gives a degree of timelessness to the three themes. The role of temporality could be an interesting topic to pursue further, particularly as an 
aspect of the "big picture," and it could probably be linked well with Bergson's (1911) notion of "creative evolution."

Our interviewees were telling us about their personal experience in their own fields, contextualized in their respective organizational settings. In turn we started to query what kind of environment could support the development as well as the ongoing research of such individuals and research groups in MOR. Perhaps creating more "hot spots" in which developing intuition and "seeing the essence" is supported would encourage such an environment. Perhaps that is the "mystery" of the conceptual leap (Klag and Langley, 2013).

\section{Funding}

The author(s) received no financial support for the research, authorship, and/or publication of this article.

\section{ORCID iD}

Viktor Dörfler (iD https://orcid.org/0000-0001-8314-4162

\section{Notes}

1. The Nobel Prize is generally regarded as the highest recognition in the fields in which they are awarded; see details of the award process at www.nobelprize.org/nomination/

2. strategyfinder, www.strategyfinder.pro

3. NVivo, www.qsinternational.com

\section{References}

Agor WH (1984a) Intuitive Management: Integrating Left and Right Brain Management Skills. Englewood Cliffs, NJ: Prentice Hall.

Agor WH (1984b) Using intuition to manage organizations in the future. Business Horizons 27(4): 49-54. DOI: 10.1016/0007-6813(84)90057-0.

Akinci C and Sadler-Smith E (2012) Intuition in management research: A historical review. International Journal of Management Reviews 14(1): 104-122. DOI: 10.1111/j.1468-2370.2011.00313.x.

Amabile TM (1982) Social psychology of creativity: A consensual assessment technique. Journal of Personality and Social Psychology 43(5): 997-1013. DOI: 10.1037/0022-3514.43.5.997.

Amabile TM (1983) The social psychology of creativity: A componential conceptualization. Journal of Personality and Social Psychology 45(2): 357-376. DOI: 10.1037/0022-3514.45.2.357.

Appadurai A (1990) Disjuncture and difference in the global cultural economy. Theory, Culture \& Society 7(2): 295-310. DOI: 10.1177/026327690007002017.

Augier M-SE and March JG (2004) Models of a Man: Essays in Memory of Herbert A. Simon. Cambridge, MA: The MIT Press.

Bergson H (1911) Creative Evolution. New York: Henry Holt and Company.

Bergson H (1946/1992) The Creative Mind: An Introduction to Metaphysics. New York: Citadel Press.

Bruner JS (1977/1999) The Process of Education. Cambridge, MA: Harvard University Press.

Butler N and Spoelstra S (2012) Your excellency. Organization 19(6): 891-903. DOI: 10.1177/1350 508412454513.

Chia RCH (1996) The problem of reflexivity in organizational research: Towards a postmodern science of organization. Organization 3(1): 31-59. DOI: 10.1177/135050849631003.

Clark TAR (1997) Advancement in Organizational Behaviour: Essays in Honour of Derek S. Pugh. Aldershot: Ashgate Publishing.

Clegg HA (1970) The System of Industrial Relations in Great Britain. Oxford: Blackwell.

Corley KG and Gioia DA (2011) Building theory about theory building: What constitutes a theoretical contribution? Academy of Management Review 36(1): 12-32. DOI: 10.5465/amr.2009.0486. 
Craft A, Gardner H and Claxton G (2008) Creativity, Wisdom, and Trusteeship: Exploring the Role of Education. Thousand Oaks, CA: Corwin Press.

Cumming G (2014) The new statistics: Why and how. Psychological Science 25(1): 7-29. DOI: 10.1177 10956797613504966.

Cunliffe AL and Sadler-Smith E (2014) Cottage industries, critique and scholarship. Management Learning 45(1): 3-5. DOI: 10.1177/1350507613510827.

Dane E and Pratt MG (2007) Exploring intuition and its role in managerial decision making. Academy of Management Review 32(1): 33-54. DOI: 10.5465/AMR.2007.23463682.

Davenport TH and Prusak L (2000) Working Knowledge: How Organizations Manage What They Know. Boston, MA: Harvard Business School Press

Davis MS (1971) That's interesting!: Towards a phenomenology of sociology and a sociology of phenomenology. Philosophy of the Social Sciences 1(2): 309-344. DOI: 10.1177/004839317100100211.

Devinney TM and Siegel DS (2012) Perspectives on the art and science of management scholarship. Academy of Management Perspectives 26(1): 6-11. DOI: 10.5465/amp.2012.0001.

Dörfler V and Ackermann F (2012) Understanding intuition: The case for two forms of intuition. Management Learning 43(5): 545-564. DOI: 10.1177/1350507611434686.

Dörfler V and Eden C (2014) Research on intuition using intuition. In: Sinclair M (ed.) Handbook of Research Methods on Intuition. Cheltenham: Edward Elgar Publishing, 264-276. DOI: 10.4337/97817825459 96.00031.

Dörfler V and Eden C (2017) Becoming a Nobel Laureate: Patterns of a journey to the highest level of expertise. In: AoM 2017: 77th annual meeting of the Academy of Management, Atlanta, GA, 4-8 August. DOI: 10.5465/AMBPP.2017.12982abstract.

Dörfler V and Stierand M (2017) The underpinnings of intuition. In: Liebowitz J, Paliszkiewicz J and Gołuchowski J (eds) Intuition, Trust, and Analytics. Boca Raton, FL: CRC Press, 3-20.

Dörfler V, Baracskai Z and Velencei J (2009) Knowledge levels: 3-D model of the levels of expertise. In: AoM 2009: 69th annual meeting of the Academy of Management, Chicago, IL, 7-11 August.

Dreyfus HL and Dreyfus SE (1986/2000) Mind Over Machine. New York: The Free Press.

Eden C and Huxham C (1996) Action research for management research. British Journal of Management 7(1): 75-86. DOI: 10.1111/j.1467-8551.1996.tb00107.x.

Eden C and Huxham C (2006) Researching organizations using action research. In: Clegg SR, Hardy C, Lawrence TB, et al. (eds) Handbook of Organization Studies. 2nd edn. London: SAGE, 388-408.

Eisenhardt KM (1989) Building theories from case study research. Academy of Management Review 14(4): 532-550. DOI: $10.2307 / 258557$.

Eisenhardt KM and Graebner ME (2007) Theory building from cases: Opportunities and challenges. Academy of Management Journal 50(1): 25-32. DOI: 10.5465/amj.2007.24160888.

Ericsson KA (1996) The acquisition of expert performance: An introduction to some of the issues. In: Ericsson KA (ed.) The Road to Excellence: The Acquisition of Expert Performance in the Arts and Sciences, Sports, and Games. Hillsdale, NJ: Lawrence Erlbaum Associates, 1-50.

Ericsson KA and Charness N (1994) Expert performance: Its structure and acquisition. American Psychologist 49(8): 725-747. DOI: 10.1037/0003-066X.49.8.725.

Ericsson KA and Crutcher RJ (1990/2014) The nature of exceptional performance. In: Baltes PB, Featherman DL and Lerner RM (eds) Life-Span Development and Behavior. New York: Psychology Press, 187-217.

Ericsson KA, Krampe RT and Tesch-Römer C (1993) The role of deliberate practice in the acquisition of expert performance. Psychological Review 100(3): 363-406. DOI: 10.1037/0033-295x.100.3.363.

Eriksson P and Kovalainen A (2008) Qualitative Methods in Business Research. Thousand Oaks, CA: SAGE. Feyerabend PK (1987/2002) Farewell to Reason. New York: Verso.

Feyerabend PK (1993/2002) Against Method. London: Verso.

Flanders AD (1970) Management and Unions: The Theory and Reform of Industrial Relations. London: Faber.

Fontana A and Frey JH (1994) Interviewing: The art of science. In: Denzin NK and Lincoln YS (eds) The SAGE Handbook of Qualitative Research. Thousand Oaks, CA: SAGE, 361-376. 
Forrester JW (1958) Industrial dynamics: A major breakthrough for decision makers. Harvard Business Review 36(4): 37-65.

Forrester JW (1994) System dynamics, systems thinking, and soft OR. System Dynamics Review 10(2-3): 245-256. DOI: $10.1002 / \mathrm{sdr} .4260100211$.

Gadamer H-G (1975) Hermeneutics and social science. Cultural Hermeneutics 2(4): 307-316. DOI: 10.1177 /019145377500200402.

Gioia DA and Chittipeddi K (1991) Sensemaking and sensegiving in strategic change initiation. Strategic Management Journal 12(6): 433-448. DOI: 10.1002/smj.4250120604.

Gioia DA and Thomas JB (1996) Identity, image, and issue interpretation: Sensemaking during strategic change in academia. Administrative Science Quarterly 41(3): 370-403. DOI: 10.2307/2393936.

Gioia DA, Corley KG and Hamilton AL (2013) Seeking qualitative rigor in inductive research: Notes on the Gioia methodology. Organizational Research Methods 16(1): 15-31. DOI: 10.1177/1094428112452151.

Gobet F and Simon HA (1996a) Recall of random and distorted chess positions: Implications for the theory of expertise. Memory \& Cognition 24(4): 493-503. DOI: 10.3758/BF03200937.

Gobet F and Simon HA (1996b) Templates in chess memory: Mechanism for re-calling several boards. Cognitive Psychology 31(1): 1-40. DOI: 10.1006/cogp.1996.0011.

Gobet F and Simon HA (2000) Five seconds or sixty? Presentation time in expert memory. Cognitive Science 24(4): 651-682. DOI: 10.1016/S0364-0213(00)00031-8.

Gummesson E (2006) Qualitative research in management: Addressing complexity, context and persona. Management Decision 44(2): 167-179. DOI: 10.1108/00251740610650175.

Hadamard J (1954) The Psychology of Invention in the Mathematical Field. New York: Dover Publications.

Heidegger M (1927/1996) Being and Time. New York: Harper.

Hillon ME and Boje DM (2007) The social ecology of action research. Management Research News 30(5): 359-367. DOI: 10.1108/01409170710746355.

Hodgkinson GP and Healey MP (2008) Toward a (pragmatic) science of strategic intervention: Design propositions for scenario planning. Organization Studies 29(3): 435-457. DOI: 10.1177/0170840607088022.

Ingold T (2011) Being Alive: Essays on Movement, Knowledge and Description. Abingdon: Routledge.

Johnson P, Buehring A, Cassell C, et al. (2006) Evaluating qualitative management research: Towards a contingent criteriology. International Journal of Management Reviews 8(3): 131-156. DOI: 10.1111/j.14682370.2006.00124.x.

Kahneman D and Klein G (2009) Conditions for intuitive expertise: A failure to disagree. American Psychologist 64(6): 515-526. DOI: 10.1037/a0016755.

Kilduff M (2006) Editor's comments: Publishing theory. Academy of Management Review 31(2): 252-255. DOI: 10.5465/AMR.2006.20208678.

Kilduff M, Mehra A and Dunn MB (2011) From blue sky research to problem solving: A philosophy of science theory of new knowledge production. Academy of Management Review 36(2): 297-317. DOI: 10.5465/amr.2009.0164.

Klag M and Langley A (2013) Approaching the conceptual leap in qualitative research. International Journal of Management Reviews 15(2): 149-166. DOI: 10.1111/j.1468-2370.2012.00349.x.

Klein G (2004) The Power of Intuition: How to Use Your Gut Feelings to Make Better Decisions at Work. New York: Doubleday Currency.

Kvale S (1994) Ten standard objections to qualitative research interviews. Journal of Phenomenological Psychology 25(2): 147-173. DOI: 10.1163/156916294X00016.

Lee B and Cassell C (2013) Research methods and research practice: History, themes and topics. International Journal of Management Reviews 15(2): 123-131. DOI: 10.1111/ijmr.12012.

McInnes P, Hibbert P and Beech N (2007) Exploring the complexities of validity claims in action research. Management Research News 30(5): 381-390. DOI: 10.1108/01409170710746373.

March JG (1994) Primer on Decision Making: How Decisions Happen. New York: Free Press.

March JG (2008) Three eras in theories of choice: A few ruminations of an ancient mariner (MOC distinguished scholar address). In: AoM 2008: 68th annual meeting of the Academy of Management, Anaheim, CA, 8-13 August.

March JG and Simon HA (1993) Organizations. Oxford: Blackwell. 
Mead M (1959) People and Places. New York: Bantam Pathfinder.

Mintzberg H (2005) Developing theory about the development of theory. In: Smith KG and Hitt MA (eds) Great Minds in Management: The Process of Theory Development. Oxford: Oxford University Press, $355-372$.

Nakamura J, Shernoff DJ and Hooker CH (2009) Good Mentoring: Fostering Excellent Practice in Higher Education. San Francisco, CA: Jossey-Bass.

Pandza K and Thorpe R (2010) Management as design, but what kind of design? An appraisal of the design science analogy for management. British Journal of Management 21(1): 171-186. DOI: 10.1111/j.14678551.2008.00623.x.

Perl M (2009) Matter, Energy, and the Universe (Keynote talk), VIPSI 2009 Belgrade, Belgrade, Serbia, 2-5 April.

Pettigrew AM (1985) The Awakening Giant: Continuity and Change in Imperial Chemical Industries. Oxford: Routledge Revivals Series.

Pettigrew AM (1990) Longitudinal field research on change: Theory and practice. Organization Science 1(3): 267-292. DOI: 10.1287/orsc.1.3.267.

Pettigrew AM (1992) The character and significance of strategy process research. Strategic Management Journal 13: 5-16. DOI: 10.1002/smj.4250130903.

Pettigrew AM (1997) What is a processual analysis? Scandinavian Journal of Management 13(4): 337-348. DOI: 10.1016/s0956-5221(97)00020-1.

Phillips DL (1973) Abandoning Method: Sociological Studies in Methodology. San Francisco, CA: JosseyBass.

Poincaré H (1914/2008) Science and Method. London: Thomas Nelson and Sons.

Polányi M (1962a/2002) Personal Knowledge: Towards a Post-Critical Philosophy. London: Routledge.

Polányi M (1962b) The republic of science: Its political and economic theory. Minerva 1(1): 54-73. DOI: 10.1007/BF01101453.

Polányi M (1966/1983) The Tacit Dimension. Gloucester, MA: Peter Smith.

Popper KR (1968/2004) The Logic of Scientific Discovery. London: Routledge.

Pratt MG (2008) Fitting oval pegs into round holes: Tensions in evaluating and publishing qualitative research in top-tier North American journals. Organizational Research Methods 11(3): 481-509. DOI: $10.1177 / 1094428107303349$.

Prusak L (2004) What you can and what you cannot do in knowledge management? (Keynote talk). In: Conference on information science, technology management, Alexandria, Egypt, 8-10 July.

Pugh DS, Hickson DJ, Hinings CR, et al. (1968) Dimensions of organization structure. Administrative Science Quarterly 13(1): 65-105. DOI: 10.2307/2391262.

Pugh DS, Hickson DJ, Hinings CR, et al. (1969) The context of organization structures. Administrative Science Quarterly 14(1): 91-114. DOI: 10.2307/2391366.

Riley M, Wood RC, Clark MA, et al. (2000) Researching and Writing Dissertations in Business and Management. London: Thomson Learning.

Sadler-Smith E (2008) Inside Intuition. London: Routledge.

Sadler-Smith E and Shefy E (2004) Developing intuition: "Becoming smarter by thinking less." Academy of Management Proceedings 2004: C1-C6. DOI: 10.5465/AMBPP.2004.13862598.

Simon HA (1974) How big is a chunk? Science 183: 482-488. DOI: 10.1126/science.183.4124.482.

Simon HA (1987) Making management decisions: The role of intuition and emotion. Academy of Management Executive 1(1): 57-64. DOI: 10.5465/AME.1987.4275905.

Simon HA (1996) The Sciences of the Artificial. Cambridge, MA: The MIT Press.

Simon HA and Chase WG (1973) Skill in chess: Experiments with chess-playing tasks and computer simulation of skilled performance throw light on some human perceptual and memory processes. American Scientist 61(4): 394-403. DOI: 10.2307/27843878.

Sinclair M (2011) An integrated framework of intuition. In: Sinclair M (ed.) Handbook of Intuition Research. Cheltenham: Edward Elgar Publishing, 3-16. DOI: 10.4337/9780857936370.

Sinclair M and Ashkanasy NM (2005) Intuition: Myth or a decision-making tool? Management Learning 36(3): 353-370. DOI: 10.1177/1350507605055351. 
Smith WK and Lewis MW (2011) Toward a theory of paradox: A dynamic equilibrium model of organizing. Academy of Management Review 36(2): 381-403. DOI: 10.5465/amr.2009.0223.

Spender J-C (2013) Herbert Alexander Simon: Philosopher of the organizational life-world. In: Witzel M and Warner M (eds) The Oxford Handbook of Management Theorists. Oxford: Oxford University Press, 297-357. DOI: 10.1093/oxfordhb/9780199585762.013.0015.

Stierand M (2015) Developing creativity in practice: Explorations with world-renowned chefs. Management Learning 46(5): 598-617. DOI: 10.1177/1350507614560302.

Suddaby R (2014) Editor's comments: Why theory? Academy of Management Review 39(4): 407-411. DOI: 10.5465/amr.2014.0252.

Thorpe R, Eden C, Bessant J, et al. (2011) Rigour, relevance and reward: Introducing the knowledge translation value-chain. British Journal of Management 22(3): 420-431. DOI: 10.1111/j.1467-8551.2011.00760.x.

Tsoukas H (2005a) Complex Knowledge: Studies in Organizational Epistemology. Oxford: Oxford University Press.

Tsoukas H (2005b) Do we really understand tacit knowledge? In: Tsoukas H (ed.) Complex Knowledge: Studies in Organizational Epistemology. Oxford: Oxford University Press, 141-161.

Tsoukas H and Chia RCH (2002) On organizational becoming: Rethinking organizational change. Organization Science 13(5): 567-582. DOI: 10.1287/orsc.13.5.567.7810.

van Aken JE (2005) Management research as a design science: Articulating the research products of mode 2 knowledge production in management. British Journal of Management 16(1): 19-36. DOI: 10.1111/j.1467-8551.2005.00437.x.

van de Ven AH and Johnson PE (2006) Knowledge for theory and practice. Academy of Management Review 31(4): 802-821. DOI: 10.5465/amr.2006.22527385.

von Hayek FA (1942) Scientism and the study of society. Part I. Economica 9(35): 267-291. DOI: $10.2307 / 2549540$.

von Hayek FA (1943) Scientism and the study of society. Part II. Economica 10(37): 34-63. DOI: $10.2307 / 2549653$.

von Hayek FA (1944) Scientism and the study of society. Part III. Economica 11(41): 27-39. DOI: $10.2307 / 2549942$.

Weick KE (1979) The Social Psychology of Organizing. New York: McGraw-Hill.

Weick KE (1995a) Sensemaking in Organizations. Thousand Oaks, CA: SAGE.

Weick KE (1995b) What theory is not, theorizing is. Administrative Science Quarterly 40(3): 385-390. DOI: $10.2307 / 2393789$.

Weick KE (1999) That's moving: Theories that matter. Journal of Management Inquiry 8(2): 134-142. DOI: $10.1177 / 105649269982005$.

Weick KE and Roberts KH (1993) Collective mind in organizations: Heedful interrelating on flight decks. Administrative Science Quarterly 38(3): 357-381. DOI: 10.2307/2393372.

Whetten DA (1989) What constitutes a theoretical contribution? Academy of Management Review 14(4): 490-495. DOI: $10.5465 / \mathrm{amr} .1989 .4308371$. 


\section{Appendix I}

Table I. List of interviewees and their prizes.

\begin{tabular}{|c|c|}
\hline Name & Prize(s) \\
\hline $\begin{array}{l}\text { Kenneth J. } \\
\text { Arrow }\end{array}$ & $\begin{array}{l}\text { John Bates Clark Medal (1957), Nobel Prize in Economics (1972), von Neumann } \\
\text { Theory Prize (1986), National Medal of Science (2004) }\end{array}$ \\
\hline Paul Berg & $\begin{array}{l}\text { Nobel Prize in Chemistry (1980), Scientific Freedom and Responsibility Award } \\
\text { (1982), National Medal of Science (1983) }\end{array}$ \\
\hline $\begin{array}{l}\text { James W. } \\
\text { Cronint }\end{array}$ & $\begin{array}{l}\text { Research Corporation Award (1968), John Price Wetherill Medal (1975), Ernest } \\
\text { O. Lawrence Award (1977), Nobel Prize in Physics (1980), National Medal of } \\
\text { Science (1999) }\end{array}$ \\
\hline Michael J. Flynn & $\begin{array}{l}\text { Eckert-Mauchly Award (1992), Harry H. Goode Memorial Award (1995), IEEE } \\
\text { Computer Society Golden Core Award (1996), Tesla Medal (1998) }\end{array}$ \\
\hline Robert W. Fogel ${ }^{\dagger}$ & Nobel Prize in Economics (1993) \\
\hline $\begin{array}{l}\text { Sheldon L. } \\
\text { Glashow }\end{array}$ & George Ledlie Award (1978), Nobel Prize in Physics (1979) \\
\hline Roy J. Glauber ${ }^{\dagger}$ & $\begin{array}{l}\text { Michelson Medal (1985), Max Born Award (1985), Dannie Heineman Prize } \\
\text { (1996), Nobel Prize in Physics (2005), “Medalla De Oro del CSIC" (2008) }\end{array}$ \\
\hline David J. Gross & Dirac Medal (1988), Nobel Prize in Physics (2004) \\
\hline Daniel Kahneman & $\begin{array}{l}\text { APS Distinguished Scientific Contribution Award (1982), Nobel Prize in Economics } \\
\text { (2002), APA Lifetime Achievement Award (2007) }\end{array}$ \\
\hline $\begin{array}{l}\text { Robert E. Lucas } \\
\text { Jr. }\end{array}$ & Nobel Prize in Economics (1995) \\
\hline Yoichiro Nambu ${ }^{\dagger}$ & $\begin{array}{l}\text { National Medal of Science (1982), Dirac Medal (1986), J.J. Sakurai Prize (1994), } \\
\text { Wolf Prize in Physics (1994/1995), Nobel Prize in Physics (2008) }\end{array}$ \\
\hline George A. Olaht & Nobel Prize in Chemistry (1994), Priestley Medal (2005) \\
\hline $\begin{array}{l}\text { Douglas D. } \\
\text { Osheroff }\end{array}$ & $\begin{array}{l}\text { Simon Memorial Prize (1976), Oliver E. Buckley Prize (1981), MacArthur Prize } \\
\text { (1981), Nobel Prize in Physics (1996) }\end{array}$ \\
\hline Yale N. Patt & $\begin{array}{l}\text { Emanuel R. Piore Award (1995), IEEE Computer Society Golden Core Award } \\
\text { (1996), Eckert-Mauchly Award (1996), Wallace W. McDowell Award (1999), IEEE } \\
\text { Third Millenium Medal (2000), Charles Babbage Award (2005) }\end{array}$ \\
\hline Martin L. Perl† & Wolf Prize in Physics (1982), Nobel Prize in Physics (1995) \\
\hline $\begin{array}{l}\text { Edward C. } \\
\text { Prescott }\end{array}$ & $\begin{array}{l}\text { Alexander Henderson Award (1967), Erwin Plein Nemmers Prize in Economics } \\
\text { (2002), Nobel Prize in Economics (2004) }\end{array}$ \\
\hline $\begin{array}{l}\text { F. Sherwood } \\
\text { Rowlandt }\end{array}$ & $\begin{array}{l}\text { Tolman Medal (1976), Tyler Prize for Environmental Achievement (1983), Japan } \\
\text { Prize (1989), Peter Debye Award (1993), Roger Revelle Medal (1994), Nobel Prize } \\
\text { in Chemistry (1995) }\end{array}$ \\
\hline $\begin{array}{l}\text { Joseph H. Taylor } \\
\text { Jr. }\end{array}$ & $\begin{array}{l}\text { Heineman Prize (1980), Henry Draper Medal (1985), Tomalla Foundation Prize } \\
\text { (1987), Magellanic Premium (1990), John J. Carty Award for the Advancement of } \\
\text { Science (1991), Albert Einstein Medal (1991), Wolf Prize in Physics (1992), Nobel } \\
\text { Prize in Physics (1993), Karl Schwarzschild Medal (1997) }\end{array}$ \\
\hline Eric F. Wieschaus & Nobel Prize in Physiology or Medicine (1995) \\
\hline
\end{tabular}

tmeans that these people are deceased (since the interview). 